\title{
Hydraulic characteristics of bentonite cake fabricated on cutoff walls
}

DOI:

10.1346/CCMN.2012.0600601

Link to publication record in Manchester Research Explorer

\section{Citation for published version (APA):}

Jefferis, S. A., \& Lam, C. (2012). Hydraulic characteristics of bentonite cake fabricated on cutoff walls. Clays and Clay Minerals, 60(6), 557-560. https://doi.org/10.1346/CCMN.2012.0600601

\section{Published in:}

Clays and Clay Minerals

\section{Citing this paper}

Please note that where the full-text provided on Manchester Research Explorer is the Author Accepted Manuscript or Proof version this may differ from the final Published version. If citing, it is advised that you check and use the publisher's definitive version.

\section{General rights}

Copyright and moral rights for the publications made accessible in the Research Explorer are retained by the authors and/or other copyright owners and it is a condition of accessing publications that users recognise and abide by the legal requirements associated with these rights.

\section{Takedown policy}

If you believe that this document breaches copyright please refer to the University of Manchester's Takedown Procedures [http://man.ac.uk/04Y6Bo] or contact uml.scholarlycommunications@manchester.ac.uk providing relevant details, so we can investigate your claim.

\section{OPEN ACCESS}




\title{
LETTER TO THE EDITOR
}

\section{HYDRAULIC CHARACTERISTICS OF BENTONITE CAKE FABRICATED ON CUTOFF WALLS}

\author{
Stephan A. Jefferis ${ }^{1,2}$ and Carlos $\mathrm{Lam}^{3}$ * \\ ${ }^{1}$ Environmental Geotechnics Ltd, St Mary’s Grove, 4 Adderbury Park, Adderbury, Banbury, Oxfordshire OX17 3EN, UK \\ 2 Department of Engineering Science, University of Oxford, Parks Road, Oxford, Oxfordshire OX1 3PJ, UK \\ ${ }^{3}$ School of Mechanical, Aerospace and Civil Engineering, The University of Manchester, Manchester M13 9PL, UK
}

Key Words-Bentonite, Cutoff Wall, Filter Cake, Gel Strength, Viscosity.

\section{INTRODUCTION}

Nguyen et al. (2012) presented an interesting paper concerning the fundamental and hydraulic properties of three commercial bentonites and have provided some unusual interpretations. They are to be commended for obtaining a substantial amount of filter-cake data from a relatively simple commercial instrument - the American Petroleum Institute (API) fluid-loss apparatus. However, the present authors question whether the API fluid-loss apparatus has sufficient resolution to justify the detailed analyses and conclusions that the authors present. The present authors also have reservations about the original authors' viscosity test results and the use of the viscosity-time relationship for the interpretation of the fluid-loss results.

\section{SLURRY VISCOSITY}

Suitability of the vibro viscometer

The authors present viscosity-time plots for three commercial bentonites at concentrations of 4,6 , and $8 \%$ (figure 2 of Nguyen et al., 2012). The reported slurry viscosities are from investigations with a sine-wave vibro viscometer (A\&D Company Ltd, 2008). This viscometer is a relatively new instrument based on a tuning-fork vibration principle. It measures what the manufacturer refers to as the "static viscosity" of the fluid, which is defined as the product of the viscosity and the fluid density. The present authors have concerns about the suitability of this instrument for measuring the viscosity of non-Newtonian fluids such as bentonite slurries which can show significant viscoelastic beha-

* E-mail address of corresponding author: carlos.lam@manchester.ac.uk

DOI: 10.1346/CCMN.2012.0600601 vior. For these fluids the authors' (static) viscosity will be a function of both the elastic and viscous properties of the material. Furthermore, unlike conventional viscometers, which are based on the measuring principles of concentric cylinders, cone and plate, capillary, etc., the viscosity value from the authors' instrument cannot be associated with a shear rate. The viscosity of nonNewtonian fluids such as a bentonite slurry is very dependent on the applied shear rate and unless the shear rate is known the viscosity data are of little use for the interpretation of the fluid behavior. To illustrate this point, the viscosity of a $4 \% \mathrm{Na}$-activated bentonite slurry was measured at four different shear rates (Figure 1), using a Bohlin Gemini rheometer (Malvern Instruments, UK) equipped with a cone-and-plate geometry. According to the supplier, Tolsa UK, the bentonite used was not treated with any polymer (M. Smith, pers. comm., 2012). The results show that the viscosity of this bentonite slurry depends heavily on the applied shear rate. Similar results were reported by Darley and Gray (1988), a reference cited by the authors. These results raise the question as to what shear rate the authors' viscosity data actually relate and how shear rate in addition to viscoelastic behavior has affected the values presented.

\section{Observed minima with the DY-100S bentonite slurries}

When interpreting the viscosity results (figure 2 of Nguyen et al., 2012), the authors attributed the minima shown by the DY-100S bentonite slurries to the absence of carboxymethyl cellulose (CMC). This is a novel and indeed an unexpected finding because, to the best of the present authors' knowledge, it has not been reported elsewhere in the literature. As this finding is also used by the authors to interpret the fluid-loss test results, further discussion is appropriate. A search in the literature revealed that many previous researchers have reported at first a rapid and then a gradual increase in the viscosity or gel strength of bentonite slurries with time 


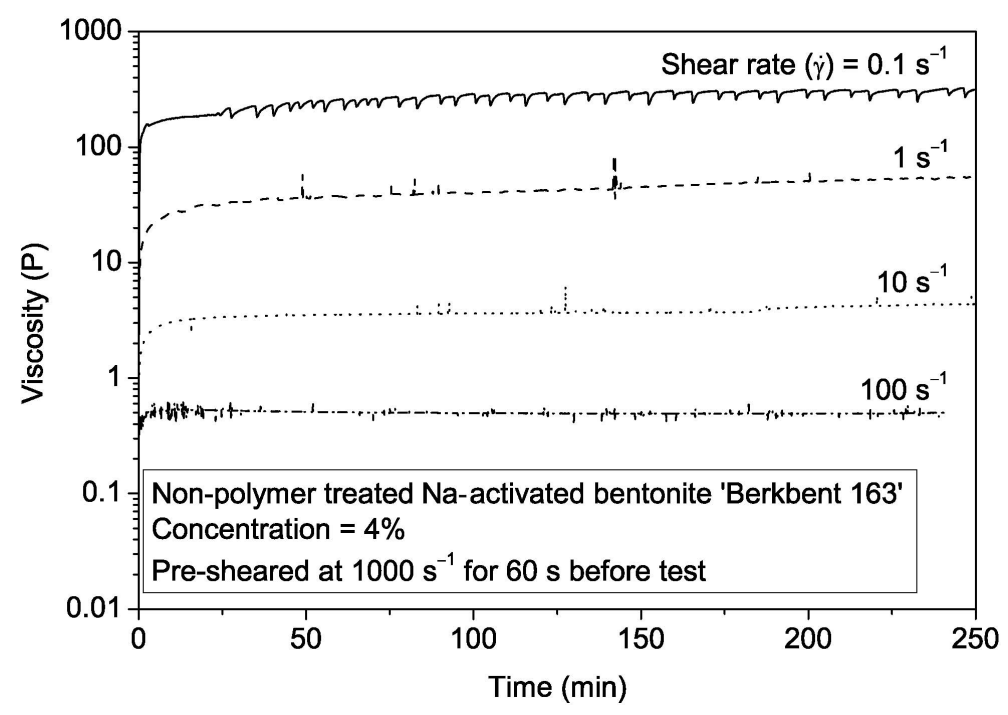

Figure 1. Viscosity curves of a non-polymer treated bentonite at four different shear rates.

for a wide range of test conditions (e.g. Garrison, 1939; Jefferis, 1982; Speers et al., 1987). This phenomenon is commonly attributed to, among other factors, the development of linkages between the clay particles to form a house-of-cards structure (Darley and Gray, 1988). This process can continue for months if the slurry is left undisturbed as shown in the experiments of Jefferis (1982). None of these previous studies shows a minimum in the viscosity (or gel strength or shear modulus) curve. In addition, the present authors' viscosity curves (Figure 1) have also demonstrated that, even in the absence of polymers, bentonite slurries still behave in a similar way.

For the reasons above, the present authors suggest that the absence of CMC is, therefore, unlikely to be the reason for the observed minima with the DY-100S slurries; two possible explanations for the original authors' results are given below. First, the authors state that the large plagioclase content of the DY-100S bentonite "may hinder the sensor vibration of the A\&D ${ }^{\circledR}$ SV-10 sine-wave vibro viscometer due to larger friction." If a stiffer system can influence the results, the observed viscosity minima could then be an artefact of the test instrument and the gelling fluids as the vibration may not be kept constant. Second, the variation in the measured static viscosity could also be the result of variations in the coupling between the tuning fork heads of the viscometer and the gelling fluid. Oscillation of the heads may cause a slight separation between the heads and the gel - a space that can become filled with bleed water. Jefferis (1982) found that when measuring shear-wave velocities it was important to isolate the test rig from shocks and knocks which can cause a substantial reduction in the apparent wave velocity. Izumo and Oda (2008) stated that slippage between the fluid specimen and the oscillator is a possible cause of reduction in the measured (static) viscosity value.

\section{FILTER-CAKE PROPERTIES}

\section{Sensitivity of the API fluid-loss cell}

In relation to filter-cake development, the authors state in their Results and Discussion section that "the overall $70 \mathrm{kPa}$ pressure was not large enough to cause any filtrate flow for the $8 \%$ slurries." As written, this implies that the cake showed a critical gradient below which no flow occurred and that an applied pressure of $70 \mathrm{kPa}$ was insufficient to overcome this no-flow gradient. For a 2$\mathrm{mm}$ cake, this gradient would have had to be $>3500$, which is difficult to accept, as indeed is any critical gradient. Perhaps the authors intended to say that no measurable flow was observed from the API cell within the test duration. This highlights two problems with the API cell when attempts are made to use it for low flows: (1) the apparatus is of limited resolution as measuring flows to better than $0.1 \mathrm{~mL}$ is difficult whereas, for purpose-designed permeameters, precision volumechange gauges can be used with much finer resolution; (2) a dead volume is present beneath the screen that supports the filter paper in the cell. This volume must be at least partially filled before any discharge from the cell will occur. For slurries of high fluid loss, this volume may be sufficiently filled in the time needed to load the cell with slurry, close it, and apply the required pressure. The dead volume may account for the negative intercepts seen in figure $3 \mathrm{~b}$ of the paper under discussion (noted by the authors but not explained) and, hence, the apparently negative filter paper resistances $\left(R_{\mathrm{m}}<0\right)$. Unless the dead volume was accounted for in the tests, the results for the filter cake resistance may not be reliable. 
The use of viscosity-time relationships to explain permeability test results

In the Summary and Conclusions section at point (3), the authors state that the higher filter-cake permeability (hydraulic conductivity) of the DY-100S bentonite was "because coagulation required a longer time after mixing." For this statement to be valid, the duration of the fluid-loss tests needs to be shorter than the coagulation times, which were 30,10 , and $90 \mathrm{~min}$ for 4,6 , and $8 \%$ bentonite concentrations. The authors state that the duration of the fluid-loss tests was $1 \mathrm{~h}$, so that the tests were typically longer than the coagulation times for the 4 and $6 \%$ slurries but shorter than that for the $8 \%$ slurries. The viscosity-time relationships, therefore, cannot be the sole cause of the observed differences between the fluidloss results, otherwise a noticeable change in the filtration rate around the coagulation time should have occurred, and this was not reported by the authors. Furthermore, if the viscosity of the slurry is a significant parameter for filtration, the difference in permeability between the three bentonites at $6 \%$ concentration should be small because their viscosities are very similar for the first $200 \mathrm{~min}$, which is longer than the duration of the fluid-loss test (1 $\mathrm{h})$. However, as shown in figures $5 \mathrm{~b}$ and $6 \mathrm{~b}$ of the discussed paper, the cake permeability of the DY-100S bentonite was significantly greater than those of the two CMC-treated bentonites (Tixoton and Bentonil GTC4). The present authors believe that the combined effects of the lower montmorillonite content and the absence of $\mathrm{CMC}$, which is a well recognized fluid-loss control agent, are amply sufficient to explain the greater permeability of the DY-100S filter cake.

\section{Possible effect of spurt loss on filter-cake thickness}

In the Summary and Conclusions at point (4), the authors discuss the overestimation of the cake thickness and attribute it to the spurt loss. However, a closer examination of the results reveals that only the $6 \%$ slurries show a consistent trend while the 4 and $6 \%$ slurries do not (figure 10 of Nguyen et al., 2012). This implies that the spurt-loss effect, if it is indeed the cause of the difference between measured and predicted cake thicknesses, is not consistent across bentonite concentrations. Although a spurt loss can occur at the start of a fluid-loss test, a significant loss of bentonite solids with the fluid spurt is rare, provided that the API-specified hardened filter papers are used. This is because a filter cake is formed during the spurt as it is during the later filtration stage - indeed it is cake formation which limits the spurt. If coarser, more open filter papers are used, then some solids could be lost but the amount should be small in comparison with the mass of solids in the cake after, say, 30 min of filtration.

The present authors suggest that the greatest uncertainty in the original authors' permeability analyses is actually the measurement of the effective cake thickness. This is because the actual slurry-cake interface is difficult to define (as noted by the authors) and the surface of the cake is rarely completely flat (Figure 2). With this in mind, the thickness of a filter cake can be measured meaningfully only to perhaps $0.5-1 \mathrm{~mm}$. The authors report their measured cake thickness to the nearest $0.25 \mathrm{~mm}$ (figure 10 of Nguyen et al., 2012); are they confident that their results were accurate to $0.25 \mathrm{~mm}$ ?

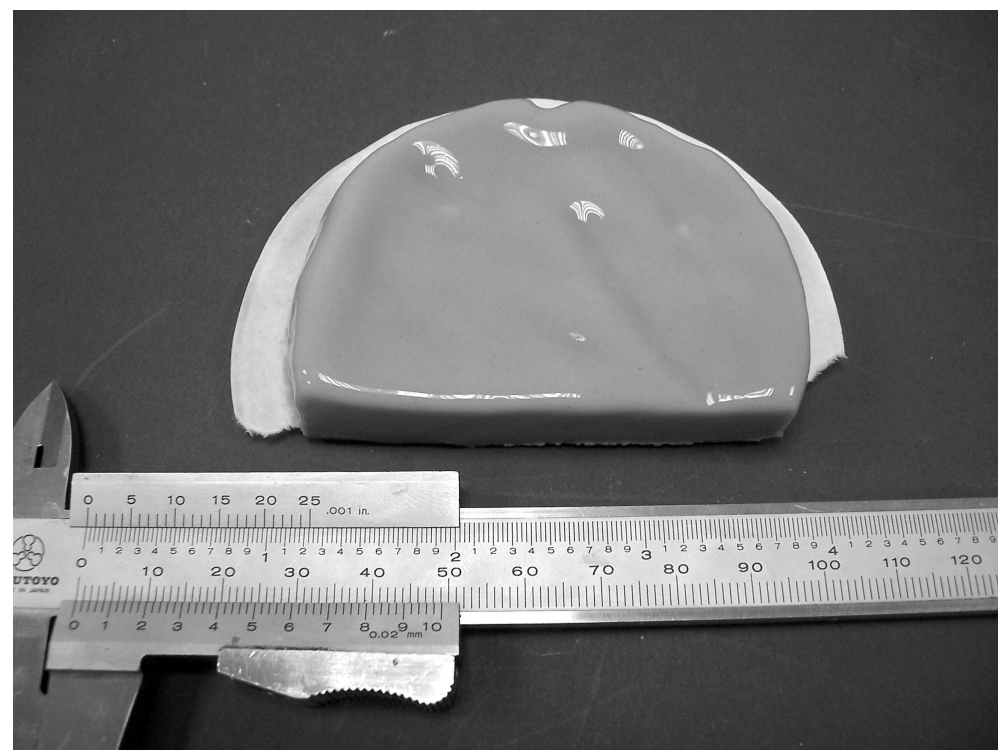

Figure 2. Photograph of a bentonite filter cake showing an indistinct and uneven slurry-cake interface at the top despite careful handling. 


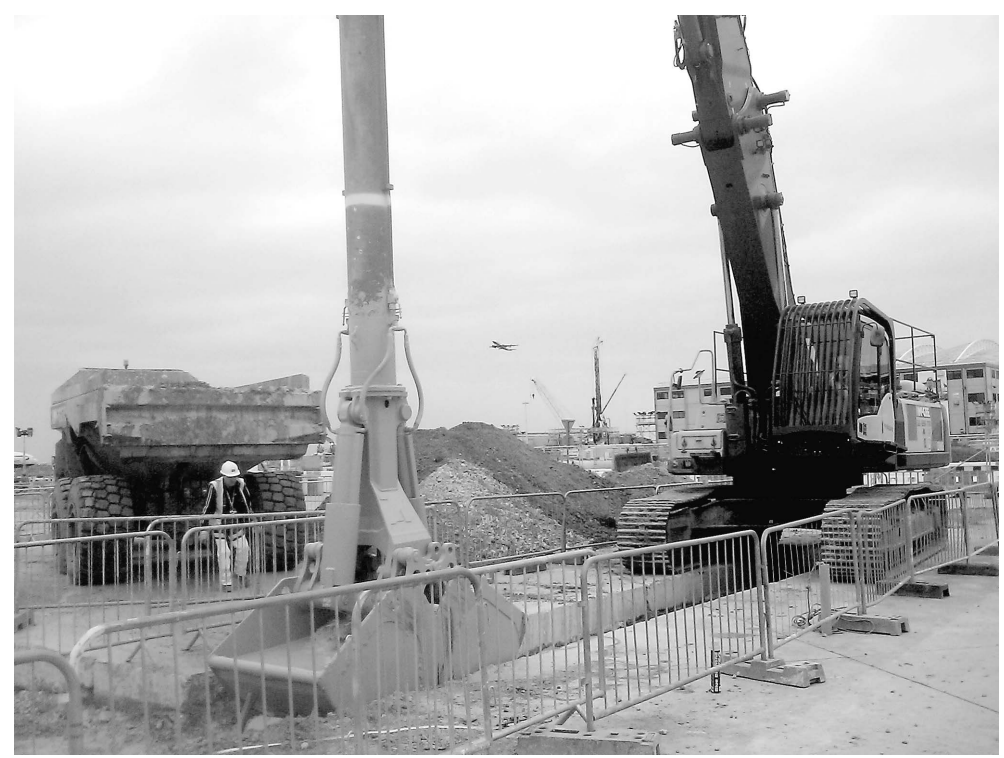

Figure 3. Possible disturbance to the under-slurry filter cake by the digging tool.

\section{APPLICATIONS TO CUTOFF WALLS}

In relation to the contribution of the filter cake to the cutoff performance of a slurry trench, although the cake may show low permeability in a laboratory experiment, this does not mean that this low permeability element will be available under field conditions. This is because, during the trench excavation, some of the filter cake will inevitably be scraped off the side walls by the digging tools (Figure 3) and may be removed, disturbed, or displaced by the rising soil-bentonite cutoff mix during backfilling of the trench. Also, are the authors confident that in service the pressure difference across a cutoff wall will not cause the cake to detach from the upstream face of the wall? The effective stress within backfills can be low and they can be significantly compressible. Given these uncertainties, the present authors support the U.S. Army Corps of Engineers (2010) recommendation that, for design, the hydraulic conductivity of the cutoff wall should be based on the backfill material only. The properties of a cutoff must be predictable, robust, and reliable.

\section{REFERENCES}

A\&D Company Ltd. (2008) SV-10 / SV-100 Vibro Viscometer Instruction Manual. A\&D Company Ltd, Japan.
Darley, H.C.H. and Gray, G.R. (1988) Composition and Properties of Drilling and Completion Fluids, $5^{\text {th }}$ edition. Gulf Professional Publishing, Houston, Texas, USA.

Garrison, A.D. (1939) Surface chemistry of clays and shales. Transactions of the AIME, 132, 423-436.

Izumo, N. and Oda. H. (2008) Observation of hardening process by static viscosity measurement of cement materials - characterization of phase change from paste to solid using the tuning fork vibration type viscosity meter. Ceramics Japan: Bulletin of the Ceramic Society of Japan, 43, 200-204 (in Japanese).

Jefferis, S.A. (1982) Effects of mixing on bentonite slurries and grouts. Pp. 62-76 in: Proceedings of ASCE Conference on Grouting in Geotechnical Engineering (W. H. Baker, editor). American Society of Civil Engineers (ASCE), New York.

Nguyen, T.-B., Lee, C., Lim, J., and Choi, H. (2012) Hydraulic characteristics of bentonite cake fabricated on cutoff walls. Clays and Clay Minerals, 60, 40-51.

Speers, R.A., Holme, K.R., Tung, M.A., and Williamson, W.T. (1987) Drilling fluid shear stress overshoot behavior. Rheologica Acta, 26, 447-452.

U.S. Army Corps of Engineers (2010) Guide Specification for Construction Soil-Bentonite (S-B) Slurry Trench. U.S. Army Corps of Engineers, UFGS-02 3527.

(Received 8 November 2012; Ms. 709) 